\title{
Effects of varying levels of thermostable xylanase, amylase and protease (TXAP) composite enzyme supplement on body growth of broiler chickens
}

\author{
A.M. Ngxumeshe ${ }^{\#}$ and R.M. Gous \\ Animal and Poultry Science, School of Agriculture and Agribusiness, University of KwaZulu-Natal, \\ Scottsville 3209, South Africa
}

\begin{abstract}
A dose-response experiment was conducted with Ross broiler chickens from day-old to 42d of age to determine the effect of exogenous composite enzyme (TXAP) on broiler performance and the most beneficial rate of inclusion. Broiler chickens were fed maize-soyabean based feed with one diet unsupplemented and five other diets supplemented with increasing levels of TXAP, from 0.5 to $2.5 \mathrm{~g} / \mathrm{kg}$. The inclusion of TXAP did not have any significant improvement on broiler performance. The lack of response in this experiment might be due to the quality of ingredients used.
\end{abstract}

Keywords: TXAP, broiler performance, exogenous composite enzymes, maize-soybean feeds.

${ }^{\#}$ Corresponding author. Email: angxumeshe@yahoo.com

\section{Introduction}

The nutrient consistency and digestibility of maize-soyabean poultry feeds have generally been considered as high and adequate. However, recent data indicate that there is room for improvement. Commercial maize and soyabean meal samples have shown a high degree of variability in terms of feeding value measured as metabolizable energy (ME) (Ghazi et al., 2003; Iji et al., 2003). Research focusing on the bird's endogenous enzymes (Classen \& Bedford, 1999) suggests that the young bird might be limited in the types and amounts of enzymes necessary to utilize a high carbohydrate and vegetable protein diet at an early age, thus affecting nutrient digestibility.

Exogenous enzymes have been used commercially for a number of years to improve nutrient digestibility in maize-soyabean feeds and to supplement the bird's developing endogenous enzyme function. One constraint to the use of exogenous enzymes in feeds is that enzymes are generally heat-labile (Jongbloed et al., 1992). Activity is reduced or lost, especially when feeds are pelleted. This has led to the development of cold-pelleting machines, operating at moderately high temperature. More recently, thermostable microbial enzymes have been developed that can withstand the effects of high temperature during feed processing. The thermostable, composite enzyme consisting of xylanase, amylase and protease (TXAP), developed by Finnfeeds is an example of such an enzyme. This enzyme is specifically intended for use in maize-soyabean based poultry feeds.

Positive responses to the addition of Avizyme ${ }^{\mathrm{TM}}$, a predecessor of TXAP, have been reported in a number of research studies with laying hens in terms of reduced diet cost (Cook et al., 2000; Gonzales et al., 2001), feed conversion ratio (FCR) improvement, liveability (Cook et al., 2000); and egg weight (Gonzales et al., 2001). In broilers and ducks, improvements in FCR, body weight, uniformity and nutrient digestibility (Zanella et al., 1999; Hong et al., 2002) were reported.

The aim of this study was to determine the effectiveness of the newly developed heat tolerant enzyme TXAP on the performance of broiler chickens fed maize-soyabean feeds. Furthermore, the rate of supplementation of this enzyme in broiler chicken feeds, for them to be fully beneficial in improving performance and diet quality, was to be determined.

\section{Materials and Methods}

A completely randomised block design was used. There were three blocks, which were chosen down the length of the house, to account for variation in temperature that prevails in a longitudinally ventilated house. There were six dietary treatments each replicated eight times (six replicates being males and two being females), with each pen of 50 birds representing a replicate. The pens measured $5 \mathrm{~m}^{2}$, yielding a stocking density of 10 -birds $/ \mathrm{m}^{2}$ at six weeks of age. Temperature was reduced stepwise from $31{ }^{\circ} \mathrm{C}$ at day- 
old to $21{ }^{\circ} \mathrm{C}$ at day 21, and maintained there for the rest of the experimental period. The humidity in the house was dependent on exchange of air provided by the tunnel ventilation system.

Two thousand four hundred sexed day-old Ross chicks were used for this study. The chicks were randomly allocated to 48 pens in groups of 50 and assigned to one of the six dietary treatments. The control diet (Treatment 1) contained no exogenous enzyme supplement while the five other Feeds (Treatments 2 to 6) contained increasing rates of inclusion of enzyme TXAP, at 0.5, 1.0, 1.5, 2.0 and $2.5 \mathrm{~g} / \mathrm{kg}$, respectively. Two basal feeds (starter and finisher) were based on maize and soyabean meal (Table 1) and were formulated to contain low levels of energy and available phosphorus to see if there were any additive effects of TXAP on energy and phosphorus availability.

The enzyme, TXAP, was obtained from Danisco Animal Nutrition (Finnfeeds International, UK). It is a mixture of xylanase, amylase and protease with guaranteed minimum enzyme activities of $600 \mathrm{U} / \mathrm{g}$ of endo-1,4 beta-xylanase (EC 3.2.1.8), $8000 \mathrm{U} / \mathrm{g}$ of subtilisin (protease) (EC 3.4.21.62) and $800 \mathrm{U} / \mathrm{g}$ of alphaamylase (EC 3.2.1.1).

Table 1 Ingredient and nutrient composition of the basal diet $(\mathrm{g} / \mathrm{kg})$

\begin{tabular}{lcc}
\hline & Starter & Finisher \\
\hline Ingredient & & \\
Maize & 613.5 & 636.0 \\
Soyabean oilcake meal & 334.9 & 285.8 \\
Sunflower oil & 13.1 & 41.9 \\
Salt & 4.1 & 3.3 \\
Lysine-HCl & 6.0 & 9.0 \\
DL Methionine & 2.1 & 1.4 \\
Limestone & 11.9 & 11.5 \\
Dicalium phosphate & 14.8 & 14.2 \\
Vit / Min premix ${ }^{1}$ & 5.0 & 5.0 \\
Nutrients & & \\
Crude protein & 215.0 & 193.6 \\
ME MJ/kg & 12.6 & 13.4 \\
Calcium & 9.0 & 8.6 \\
Available phosphorus & 4.0 & 3.8 \\
Methionine & 5.5 & 4.5 \\
TSAA & 9.1 & 7.7 \\
Lysine & 12.0 & 10.8 \\
Fat & 41.1 & 68.8 \\
Crude fibre & 21.6 & 25.0 \\
Sodium & 1.8 & 1.5 \\
\end{tabular}

${ }^{1}$ Composition of the premix (g/kg): Vitamin B1 (2), B2 (6), B6 (5), K (3), Choline chloride (300), Niacin (70), Pantothenic acid (15), Oxiban, antioxidant (125). Other nutrients are (mg/kg): Vitamin B12 (20), Biotin (150), Cobalt (500), Selenium (300), Vitamin A (MIU) (12), D3 (4).

The chicks were weighed in groups (chicks in the same pen weighed together) to obtain their body weight at day-old and subsequently every $7^{\text {th }}$ day until the end of the trial. Feed consumption was recorded at the end of each week by calculating the difference between the feed supplied at the beginning of the week and the feed that was left in the feeders and in the bag at the end of the week. Feed conversion efficiency of the birds was calculated as the ratio of the weight gained by the birds to the feed that was consumed by the birds. Mortalities were also recorded weekly on pen basis as they occurred.

Data were analysed using both the general linear model (GLM) and regression of Genstat $6^{\text {th }}$ edition (Genstat, 2002). The GLM analysis did not reveal any significant differences between the means of the tested variables. The data were regressed, using varying levels of the enzyme (TXAP) as the independent 
variable. The differences between the mean values were determined by the use of least significant difference ( $\mathrm{P}<0.05)$. Minitab software (Minitab, 2000) was used for the Chi-Squared test of the mortalities.

\section{Results}

The results of the effect of enzyme (TXAP) at different inclusion rates are presented in Table 2. The inclusion of TXAP did not significantly affect $(\mathrm{P}>0.05)$ any of the performance variables as demonstrated by analysis of variance and regression analysis (Table 3 ). The overall mortality was $2.3 \%$.

Table 2 The effects of varying inclusion rates of TXAP on body weight, feed intake, feed conversion efficiency (FCE) and mortality of broiler chicks at 42 days of age

\begin{tabular}{ccccc}
\hline Treatment & $\begin{array}{c}\text { Weight gain } \\
\left(\mathrm{g} / \mathrm{bd}^{-1}\right)\end{array}$ & $\begin{array}{c}\text { Feed intake } \\
\left(\mathrm{g} / \mathrm{bd}^{-1}\right)\end{array}$ & $\begin{array}{c}\text { FCE } \\
(\mathrm{g} / \mathrm{kg})\end{array}$ & Mortality \\
\hline & & & & \\
1 & 49.8 & 103 & 484 & 9.3 \\
2 & 50.6 & 103 & 495 & 9.3 \\
3 & 50.7 & 100 & 506 & 9.3 \\
4 & 51.0 & 100 & 511 & 9.3 \\
5 & 49.6 & 104 & 482 & 9.4 \\
6 & 51.2 & 102 & 502 & 9.3 \\
P-value & 0.230 & 0.819 & 0.250 & 0.442 \\
\hline
\end{tabular}

Table 3 The regression of the performance data of the birds at 42 days of age against TXAP

\begin{tabular}{lcc}
\hline Variable & Regression coefficient & Significance \\
\hline Weight gain (g/b d) & $0.00251 \pm 0.00258$ & NS \\
Feed intake (g/b d) & $-0.0014 \pm 0.0106$ & NS \\
FCE & $0.0329 \pm 0.0502$ & NS \\
Mortality & $-0.00068 \pm 0.00186$ & NS \\
\hline NS = Not significant. & & \\
FCE - feed conversion efficiency. & &
\end{tabular}

\section{Discussion}

The results of this experiment did not show any significant improvements caused by the inclusion of the enzyme, TXAP at any dosage rate. These results are in line with findings by Anonymous (2005), who reported an insignificant improvement in the performance traits of laying hens, but in contrast with findings by Hruby (2003), who reported dramatic improvements in the performance data through the addition of Avizyme $^{\mathrm{TM}}$, an enzyme that is similar to TXAP.

This lack of response may be attributed to the quality of maize and soyabean used in this experiment. Significant improvements are expected when supplementation is made to poor quality ingredients (Bedford, 2000; Douglas, 2000; Dudley-Cash, 2001). Research by Douglas et al. (2000), using 12 different soyabean meal sources, demonstrated that enzyme use is more beneficial in poor than in good quality ingredients.

Bedford \& Apajalahti (2000) reported that if there were healthy or beneficial microflora in the GIT, there would be no beneficial effects of the enzyme inclusion. The type of microflora present in the gastrointestinal tract (GIT) of the bird is therefore expected to play an important role in the response of the host to enzyme supplementation. 


\section{Conclusion}

This study showed no response to the inclusion of the enzyme TXAP in broiler feeds. This lack of response might be due to the quality of the ingredients used in this study. Therefore further research using ingredients with different nutritional status has to be done.

\section{References}

Anonymous, 2005. Opinion of the scientific panel on additives and products or substances used in animal feed on the safety of enzymatic product Avizyme ${ }^{\circledR} 1500$ for use as feed additive for laying hens. The EFSA Journal 171, 1-5.

Bedford, M.R., 2000. Exogenous enzymes in monogastric nutrition-their current value and future benefits. Anim. Feed Sci. Technol. 86, 1-13.

Bedford, M.R. \& Apajalahti, J., 2000. Microbial interactions in the response to exogenous enzyme utilization. In: Enzymes in Farm Animal Nutrition. pp. 299-314.

Classen, H.L. \& Bedford, M.R., 1999. The use of enzymes to improve the nutritive value of poultry feeds. In: Recent Developments in Poultry Nutrition 2. Eds Wiseman, J. \& Garnsworthy, P.C., Nottingham University Press, Nottingham, UK. pp. 285-308.

Cook, M.E., Drake, B.M. \& Pierson, E.E., 2000. Effects of Avizyme 1500 on laying hen performance. Poult. Sci. 79, Abstract.

Douglas, M.W., Parsons, C.M. \& Bedford, M.R., 2000. Effect of various soybean meal sources and Avizyme on chick growth performance and ileal digestible energy. J. Appl. Poult. Res. 9, 74-80.

Dudley-Cash, W.A., 2001. Soybean meal source, added enzyme affect nutritional value for chicks. Feedstuffs 73.

Genstat Executable 2002. Genstat statistical software. Release 6.1 Lawes Agricultural Trust.

Ghazi, S., Rooke, J.A. \& Galbraith, H., 2003. Improvement of the nutritive value of soya bean meal by protease and alpha-galactosidase treatment in broiler cockerels and broiler chicks. Br. Poult. Sci. 44, 410-418.

Gonzales, N.J., Cornejo, S., Jimenez, F. \& Lorenzoni, G., 2001. Effect of dietary supplementation with and enzyme complex (Avizyme 1500) containing amylase, xylanase and protease on performance and egg quality of commercial layers. Poult. Sci. 80, Abstract 151.

Hong, D., Burrows, H. \& Adeola, O., 2002. Addition of enzyme to starter and grower feeds for ducks. Poult. Sci. 81, 1842-1849.

Hruby, M., 2003. Enzymes reduce food poisoning bacteria. Feed Mix, 11.

Iji, P.A., Khumalo, K., Slippers, S. \& Gous, R.M., 2003. Intestinal function and body growth of broiler chickens on Feeds based on maize dried at different temperatures and supplemented with a microbial enzyme. Reproduction, Nutrition and Development 43, 77-90.

Jongbloed, A.W., Mroz, Z. \& Kemme, P.A., 1992. The effect of supplementary Aspergillus niger phytase in Feeds for pigs on concentration and apparent digestibility of dry matter, total phosphorus and phytic acid in different sections of the alimentary tract. J. Anim. Sci. 70, 1159-1168.

Minitab, 2002. Minitab release 13.1. Minitab Inc. State College, P.A.

Zanella, I., Sakomura, N.K., Silversides, F.G., Fiqueirdo, A. \& Pack, M., 1999. Effect of enzyme supplementation of broiler Feeds based on corn and soybeans. Poult. Sci. 78, 561-568. 